\title{
Reflections Regarding ICT and a Citizen-centric Future Path of Smart Sustainable Cities
}

\author{
AW4City 2018 Keynote \\ Pernilla Bergmark \\ Ericsson Research, Ericsson \\ Stockholm \\ Sweden \\ pernilla.bergmark@ericsson.com
}

\begin{abstract}
This paper looks into the use of Information and Communication Technology (ICT) for Smart Sustainable Cities (SSC). It specifically points towards ICT's potential to help cities mitigate climate change and to support a $2^{\circ} \mathrm{C}$ or lower trajectory and to involve citizens in city planning and when implementing solutions. The paper also focuses on the modelling, assessment methodologies and indicators for ICT and sustainability aspects of cities, not least with regards to climate change mitigation. Especially, it highlights the city GG emissions assessment standard by ITU, and the indicator sets from ITU and ISO and their enhancement. The paper emphasizes a sustainability and citizencentric perspective, seeing ICT as instrumental in this respect. For assessments, the above mentioned ITU-T standard is considered reusable for impacts beyond global warming. For indicators, further research on outcome and impact indicators is suggested, and also strengthening of the socio-economic and cultural aspects.
\end{abstract}

\section{KEYWORDS}

smart sustainable cities, citizen, citizen-centric, urbanization, sustainability, GHG emissions, $2{ }^{\circ} \mathrm{C}$ trajectory, carbon law, SDG, Sustainable Development Goals, city indicators, city assessment, city model, ICT, Information Communication Technology

\section{ACM Reference format:}

P. Bergmark. 2018. Reflections Regarding ICT and a Citizencentric Future Path of Smart Sustainable Cities. In The 2018 Web Conference Companion (WWW 2018), April 23-27, 2018, Lyon, France, ACM, New York, NY, 5 pages.

DOI: https://doi.org/10.1145/3184558.3191521

\section{INTRODUCTION}

The ongoing trend of global urbanization [1] is well-known and will impact societies in a profound way which has led to a great interest within academia, organizations and companies.

This paper is published under the Creative Commons Attribution-NonCommercialNoDerivs 4.0 International (CC BY 4.0) license. Authors reserve their rights to disseminate the work on their personal and corporate Web sites with the appropriate attribution.

WWW'18 Companion April 23-27, 2018, Lyon, France.

(C) 2018 IW3C2 (International World Wide Web Conference Committee), published under Creative Commons CC BY 4.0 License.

ACM ISBN 978-1-4503-5640-4/18/04.

DOI: https://doi.org/10.1145/3184558.3191521
Cities have also been associated with a major business opportunity. One forecast suggests for example a $\$ 1.5$ trillion market by 2020 , with highlighted opportunities in infrastructure development, technology integration and energy and security services [2], With commercial drivers of this magnitude, it is clear why the concept of Smart Cities has sometimes, in spite of initiatives like the New Urban Agenda by UN habitat [3], been considered to be too much focused on the city infrastructure and services - and less on the citizens, and on the environmental and social aspects of cities.

Among many city level challenges, cities need to find solutions to limit their greenhouse gas (GHG) emissions. With the rapid urbanization, cities and the citizens are bound to represent an increasing share of GHG emissions and they are therefore key to mitigate climate change. Similarly, for several other environmental challenges, cities can be considered as part of the problems but also main actors for resolving them, not least when taking a life cycle perspective. From a social perspective, cities encounter a high number of challenges, especially while expanding. UN Sustainable Development Solutions Network (UN SDSN) have illustrated this clearly in their analysis of the Sustainable Development Goals (SDG) fulfillment by US cities $[4,5]$, which shows that cities, also in the developed world, have a long way to go before being considered smart in a wider sense.

\section{CITIES AND CITIZENS}

\subsection{Smart Cities vs Smart Sustainable Cities}

ITU-T uses the concept Smart Sustainable Cities and defines it in [6] as

"an innovative city that uses information and communication technologies (ICTs) and other means to improve quality of life, efficiency of urban operation and services, and competitiveness, while ensuring that it meets the needs of present and future generations with respect to economic, social, environmental as well as cultural aspects"

Although one definition among many existing ones, and still with an improvement potential, the ITU definition lays out two important aspects i) that sustainability is, or should be, a key aspect of city development whether included in the word 'smart' or mentioned specifically, and ii) that Quality of Life (QoL) and the situation of citizens is, or should be, at the core of the concept. To highlight these 
aspects, the concept Smart Sustainable Cities (SSC) will be preferred over Smart Cities in the continuation of this text.

ITU also puts ICT as a core enabler for SSC. Such a technocentric perspective may be debated - in particular, whether technology is a means or a target for SSC. Furthermore, the focus on ICT as such may seem too narrow, as the city development demands participation of a broader range of industry sectors. However, the use of ICT could, if applied strategically, be part of the solution to societal challenges [7], through its ability to disrupt current solutions. More specifically, a substantial potential by ICT to mitigate climate change has been identified [ㅇ, $\underline{9}$ ]. In support of the Paris Agreement, Rockström et al. [10], have recently, inspired by the Moore's law, proposed a Carbon Law, to frame the decarbonization challenge in terms of a global roadmap of halving gross anthropogenic carbon-dioxide (CO2) emissions every decade, in all sectors of society. If cities enter this path remains to be seen, in any case cities need to define trajectories towards the Paris agreement. In [10], Rockström et al. clearly lay out that the carbon law (as any necessary $2^{\circ} \mathrm{C}$ or below trajectory) demands smart and disruptive action. ICT is of interest in this context due to its potential to change current behaviors and to substantially reduce GHG emissions in different sectors [ㅇ, 9$]$. Although the size of this potential may be debated [11], ICT comes with a potential to disrupt societies which could be leveraged in a strategic way by cities to mitigate climate change.

\subsection{Putting the citizens in focus}

The trend of urbanization results in an increasing population in cities representing varying needs and preferences, and on top of that cities also need to deal with their visitors and their interests. Cities compete to attract citizens through the conditions they offer and thus need to consider different groups. As an example, employment is an important factor for groups of various ages, while health becomes increasingly important with age $[\underline{12}, \underline{13}]$. As stated in [13], cities need also to be differentiated along several other axis to evaluate their needs and priorities. For example, whether cities are considered as mature, transitional or emerging will impacts their immediate priorities which may range from supplying basic needs to improving lifestyles [14]. In any case, the needs of the citizens should be understood.

Referring to the principle established by the ITU definition [6], that citizen's QoL is at the core of the SSC concept, a citizen centric perspective is fundamental to the development of cities. von Heland et al applied this lens in [15] where they studied how citizens could be engaged to maintain an ICT supported sustainable water supply in slum areas in Nairobi, Kenya. This project used ICT supported management strategies to supply fresh water, but also to strengthen public participation in governance, and was based on a novel smart water concept which combined multi-functional sensors to monitor water supply with an ICT-based governance model where smartphone-enabled local residents were employed as service engineers. The applied scenario analysis suggested that the concept, beyond improving water availability, affordability, and quality, also could improve the situation of women and suggested a positive impact on children's school attendance due to improved health. In this context, [15], supported by other research [16], suggests a conceptual shift of the urban debate from large, centralized systems to decentralized, open urban infrastructures that can drive change in a proactive, holistic and collaborative way to meet the needs of citizens. The study highlighted that enabling a dialogue between the city, citizens and businesses and allowing collaborative bottom-up creativity is an important driver for technology adaptation and urban sustainability.

ICT also offers new opportunities to engage citizens in urban design and decision making. Ericsson Research, in partnership with UN habitat, has trialed the use of ICT to increase citizens' participation in city planning. A project in Kirtipur, Nepal used Minecraft as a community participation tool to engage young people in city planning through public space design [17]. The study explored the potential of Minecraft to foster greater citizen participation in urban design and decision making, and examined social impacts associated with the use of Minecraft at individual and community levels. The results showed that Minecraft increased youth interest in urban design and was also found to encourage the development of action-oriented and intrinsic skills. However, institutional arrangements and digital skills were influencing how youth could use Minecraft for participation.

Another example on how the use of ICT could support citizen's participation is more recent and took place in Johannesburg, South Africa, again in partnership with UN habitat, but also with City of Johannesburg and Wits University [18]. Building the Public City is a project run by the City of Johannesburg that tries to solve public space challenges through integrating design and participation processes. Again, Minecraft has been used as a tool to engage with people to draft ideas for improved public spaces, without demanding prior knowledge in ICT and architecture. Building on this concept, a pilot workshop was arranged to explore how mixed reality could work as an additional component. Participants were given the task to propose improvements to an adjacent public place and modelled their proposals in a Minecraft-replica of the area. The models were then copied into a mixed reality application so that participants could go outside and view their Minecraft creations projected in real life using special smartphones enabled with sensors and 3D-sensing technology. After the workshop, some of the proposals were refined into a plan for remodeling of the whole place, which could also be explored on-site, in mixed reality. No social assessment has been performed in this case, but the example indicates the opportunities to engage citizens in co-creation processes.

Taken together these three examples show a potential of ICT to put citizens in the core of city development, both in planning and when implementing services, which could be further explored.

\section{ASSESSING THE CITIES AND THEIR ICT IMPACTS}

\subsection{City models}

A city is a highly complex structure which is not easily boiled down into one or a few models. Thus, several city models may coexist for different purposes. As an example, Lövehagen and Bondesson [13] proposed a model based on city services to be used to understand and assess ICT services in a city context. This 
proposal was based on a wide literature review which led to the conclusion that little work had been done on ICT and city level assessment methodologies. The proposed model, depicted as a house, was divided into three main blocks: i) infrastructure services (the basement), ii) community services; and, iii) noncommunity services, with the users of these services; citizens and organizations, indicated at the top-floor. In this model infrastructure services included items such as water, buildings and ICT; community services covered healthcare, education, living environment etc.; while non-community services referred to e.g. finance and workplaces. This model was introduced as a starting point and was compared to the United States (US) federal enterprise architecture reference model which lists the US governments' services to citizens [19], towards which a high degree of similarity was found.

This model can be useful to structure cities based on their services. At the same time, it is limited in the sense that it lacks both the supply of resources, such as materials and energy needed to provide the services, and the wasted resources, i.e. the model lacks inflows and outflows. Additionally, it does not cover the different actors of the cities and their interaction, and the citizens remain invisible. How usage of city services might look different in different groups of citizens is also excluded. Despite these limitations the model seems to be useful to structure cities in terms of the services offered. However, it needs to be revisited to consider whether it could be supportive when assessing measures to fulfill SDGs [4] at a city level, and to investigate how it aligns with city indicator structures proposed by ISO [20] and others, as it was developed prior to these initiatives.

\subsection{Assessment methodologies}

In 2013, Lövehagen and Bondesson concluded in [13] that a framework for assessing the impacts of ICT at a city level was lacking in spite of a high number of existing methodologies referring to the cities as such. They additionally noted that no framework held a full life cycle perspective and that a production perspective was more common than a consumption perspective.

These conclusions were based on a literature review of almost two hundred papers and reports on assessments, indicators, methodologies, and evaluation tools related to sustainability, ICT and cities, aiming for defining the term smart city and making an overview of city related sustainability evaluation frameworks. As an illustration of the very high number of existing initiatives, one reviewed paper, [21], by itself, had found over 675 tools applicable to the assessment of urban sustainability.

Based on their literature review, Lövehagen and Bondesson proposed the following requirements for assessing the impacts of ICT at a city level: Indicators should be selected to get a manageable and sufficient number of indicators both on a city level and for specific ICT solutions. The method should handle both case specific and general publicly available city data. Geographical boundaries and assessment boundaries should be transparently defined. Results should be reported separately and merging of indicators should be avoided. Finally, they proposed that a life cycle perspective and realistic scenarios should be applied. In accordance with these principles, an assessment procedure for sustainability impacts was proposed including i) identifying ICT solutions; ii) defining the system boundary for the city and a functional unit for the assessment; iii) building scenarios and assess ICT solutions at a city level; and, iv) selecting indicators to connect solution specific impact results to overall city level sustainability. Furthermore, the influence from drivers and barriers on results, and the need to consider rebound was highlighted.

Since then, assessment methods related to ICT and cities have been developed by the International Telecommunication Union (ITU) [22] with regards to climate change impacts and for different purposes i) to estimate the footprint of the use of ICT in organizations and households in the city, and ii) to estimate the enablement effect of city-scale ICT projects and services. The standard proposes two tiers of assessment where tier 2 refers to a life cycle perspective, and the assessment procedure includes five steps:

- Identification of the geographical boundaries.

- Definition of how the ICT project or ICT service is adopted within these boundaries and identify the effect of the project or service.

- Definition of the reference scenario of the service.

- Definition of system boundaries for both the ICT scenario and the reference scenario.

- Consideration of rebound risks, drivers, and barriers

The standard also outlines a methodology for estimating potential city level impacts of ICT projects or services, based on experienced impacts in pilots or in other cities. This method includes the following steps: i) to identify the reference ICT service or project and the reference city/pilot, ii) to analyze the estimated potential of the reference situation and how this potential was derived, iii) to identify the target city, city area or city region, iv) to define system boundaries for the target city and the reference, $v$ ) to define a common reference unit, vi) to select relevant high-level profile data for the target city and the reference, vii) to compare the target city and the reference pilot study or reference city, viii) to compare solution specific parameters, ix) to build a use scenario (users, use profiles, ICT) for the targeted city also using the profile data, $x$ ) to make a quantitative scaling for applicable parameters, xi) to make a qualitative analysis of other parameters, and xii) to summarize and interpret the results.

As a next step, the experiences from applying the ITU-T methodologies should be collected and analysed to evaluate their usability. Furthermore, although the ITU-T methodologies are specifically targeting GHG emissions, the different steps of the methods are considered reusable to other impact categories, which also the suggested procedure from [13], with its wider scope, implies. However, further research is needed to confirm this.

\subsection{Indicators for cities}

In [13], Lövehagen and Bondesson noted a very high number of indicator sets for cities and smart cities for the assessment of the sustainability or the environmental impact of a city. For instance, [23] listed over 600 sustainability indicator initiatives at 
global, national, regional, and local levels. From the high number of sources collected, Lövehagen and Bondesson concluded that GHG emissions and energy usage were included in almost all indicator sets, while for socioeconomic indicators there was large variety, and many unique indicators were identified.

The high number of identified indicators points towards the need for standardization, to support cities in finding homogenous and recognized indicator sets. Since then, at a global scale, the SDGs have been launched, ITU-T have published their indicators on SSC $[24, \underline{25}, \underline{26}]$ and ISO have published the first edition of their indicators for cities [20] and now work on indicators for smart cities and resilient cities [27-28].

The SDGs represent perhaps the most prominent indicator set of our time and will be adopted widely. Though not developed for cities, it has already started to gain traction at a city level [4]. From an indicator perspective, ITU-T together with UNECE have tried to develop SDG related city indicators. More generally, all indicator sets could benefit from considering the SDGs, not least as cities play a fundamental role for countries' ability to reach the goals. The standardization of city level indicators in ITU and ISO is an important step towards more widely recognized indicators. However, a drawback is that the standardization bodies mainly attracts national and sector members, while cities themselves are represented to a lower extent, i.e. there is to some extent a standardization process for cities rather than with cities, although the standardization bodies tries to take measures to involve the cities themselves in pilots etc.

At this stage the major existing indicator sets for cities could also be improved by more clearly distinguishing between indicators related to input, output, outcome, and impact. In [29], The International NGO Training and Research Centre (INTRAC) describe this chain as

"inputs are used in order to carry out activities. Activities lead to services or products delivered (outputs). The outputs start to bring about change (outcomes) and eventually this will (hopefully) contribute to the impact"

and define these categories in accordance with Organisation for Economic Co-operation and Development (OECD) [30]. Although mainly oriented towards interventions, these definitions seem to work well also for projects and solutions.

Currently, many indicators set focus more on input and output, than on outcome and impact. In a concept paper by the Overseas Development Institute (ODI) for EC DG DEVCO [31] which made a critical overview of social protection indicators in the SDG context, noted that

"the types of indicators currently used focus heavily on measuring quantity at the input and output level. This is at the expense of resultsoriented indicators which would capture social protection outcomes and impacts, and measure the quality of social protection."

In this respect, further research to systematically classify current city indicators, and, more challenging, to develop practically usable outcome and impact oriented-indicators at a city-scale, would be of help for the standardization bodies and for the cities.
With regards to the city indicator standards, it would be beneficial to seek further alignment between them as the different indicator sets are often overlapping and provide similar, yet different, indicators. Such alignment would facilitate for cities seeking guidance on indicators. Indicator standards could also be made more citizencentric. Looking at the different areas covered, one important perspective is missing or under-represented in most major city indicator sets - the situation of elderly people, although those form a fast-growing group in many countries. Furthermore, focus on cultural aspects, and social aspects such as equity and social inclusion for all citizens could be strengthened. Another room for improvement, at this stage, is to define indicators that capture the socio-economic gaps. Stockholm, a city in Sweden which is usually scoring high on equality, has collected statistics which shows considerable differences in life expectancy, oral health and health indicators related to socioeconomic status of city districts [32]. Perhaps these, or similar, parameters could be used by the standards as proxies for welfare distribution.

\section{CONCLUSIONS}

The reflections regarding SSC outlined in this paper could be summarized as follows:

- The perspective of the citizen should be further emphasized, and citizen participation should be strengthened in the development of solutions, methods, and indicators for SSC. Thus, technology is seen as a means for SSC development, not the target. In this respect, ICT may be used as a tool to engage citizens to facilitate and inspire participation, collaboration, and co-creation.

- Sustainability is a key aspect of Smart Cities, and the term Smart Sustainable Cities (SSC) highlights this.

- In particular are cities key to mitigate climate change and the Carbon Law concept, among other trajectories, suggest a pathway which half anthropogenic emissions every decade.

- In this respect, ICT, used strategically for sustainable purposes, may provide tools that could help cities and societies to mitigate climate change.

- To understand the footprint of cities demands a dual or trial lens where territorial, production and consumption perspectives are considered.

- ITU has developed methods for assessing the positive and negative ICT contributions to city climate change impacts including a method for learning and sharing experiences between cities. These methods are to large extent expected to be reusable for other environmental and socioeconomic impact categories.

- City indicators and indices are available from many sources, including ITU, ISO, and the SDGs.

- Future indicators may more clearly distinguish between indicators for input, output, outcome, and impact, and focus on moving current indicators sets towards outcome and impact. Here, research may pave the way as complex causal chains render this task difficult. 
- The socio-economic and cultural aspects of current standardized indicator sets may be strengthened, particularly the situation of elderly people is missing.

- Despite the high number of existing city-oriented initiatives, opportunities exist for cities, academia, organizations, and companies to work closer together to leverage the joint knowledge of these actors for a sustainable development of cities with regards to the environment, social aspects and the economy.

\section{ACKNOWLEDGMENTS}

The author would like to thank Nina Lövehagen, Anna Bondesson and Fanny von Heland, former employees at Ericsson Research, and Marcus Nyberg with colleagues at Ericsson Research for their dedicated research and strategic design thinking around sustainable urbanization, which provided the basis for this paper. The author also wants to thank colleagues in ITU-T SG5 for valuable discussions on city indicators and assessment methods.

\section{REFERENCES}

[1] United Nations. 2012. The future we want Cities. Fact sheet for the Rio +20 United National Conference on Sustainable Development, Rio de Janeiro,

Brazil, June 20-22, 2012. Retrieved February 2018 from http://www.un.org/en/sustainablefuture/pdf/Rio+20_FS_Cities.pdf

[2] Frost \& Sullivan. 2018. Smart Cities - A \$1.5 Trillion Market Opportunity. Retrieved February 2018 from https://ww2.frost.com/event/calendar/smart-cities-15-trillion-marketopportunity/

[3] UN Habitat. 2016. New Urban Agenda. Retrieved February 2018 from http://nua.unhabitat.org/

[4] United Nations. Sustainable Development Goals. 2016. Retrieved February 2018 from http://www.un.org/sustainabledevelopment/sustainabledevelopment-goals/

[5] Mihir Prakash, Katerina Teksoz, Jessica Espey, Jeffrey Sachs, Michael Shank

and Guido Schmidt-Traub. 2017. UN Sustainable Development Solutions Network (UN SDSN). Achieving a sustainable urban America. Retrieved February 2018 from

http://unsdsn.org/resources/publications/us-cities-sdg-index/

[6] International Telecommunication Union (ITU). 2015. Smart sustainable cities definition. Retrieved February 2018 from https://www.itu.int/en/ITU-T/ssc/Pages/info-ssc.aspx

[7] Lorenz Hilty, Wolfgang Lohmann, and Elaine M Huang. 2011. Sustainability and ICT - An overview of the field with focus on socioeconomic aspects. Notizie di Politeia, 17, 104, 13-28. DOI=http://dx.doi.org/10.5167/uzh-55640

[8] Jens Malmodin, Pernilla Bergmark. 2015. Exploring the effect of ICT solutions on GHG emissions in 2030. ICT4S 2015 conference.

[9] Global e-Sustainability Initiative. 2015. \#SMARTer2030 - ICT Solutions for 21st Century Challenges. 2015. Retrieved February 2018 from http://smarter2030.gesi.org/

[10] Johan Rockström, Owen Gaffney, Joeri Rogelj, Malte Meinshausen, Nebojsa Nakicenovic, Hans Joachim Schellnhuber. 2017. Carbon Law: A roadmap for rapid decarbonization. Science 24 Mar 2017:Vol. 355, Issue 6331, pp. 1269-1271, OI:10.1126/science.aah3443

[11] Jens Malmodin, Pernilla Bergmark, Nina Lövehagen, Mine Ercan, Anna Bondesson. 2014. Considerations for macro-level studies of ICT's enabling potential. ICT4S 2014 conference.

[12] Yukiko Uchida, Fumio Ohtake, Kohei Komamura, Yoshinori Hiroi, Yoshihiro Makino, Michiko Miyamoto, Naoto Yamauchi, and Masahiro Yamada. 2011. Measuring national well-being - proposed well-being indicators, report from the Japanese Commission on Measuring Wellbeing.

[13] Nina Lövehagen, Anna Bondesson. 2013. Evaluating sustainability of using ICT solutions in smart cities - methodology requirements. ICT4S 2013 conference.
[14] Gareth Lofthouse. (editor). 2006. Megacity challenges - a stakeholder perspective, a research project conducted by the Economist Intelligence Unit, sponsored by Siemens, Munich Germany 2006.

[15] Fanny von Heland, Anna Bondesson, Marcus Nyberg, Pontus Westerberg, 2015. The Citizen Field Engineer: Crowdsourced Maintenance of Connected Water Infrastructure - Scenarios for smart and sustainable water futures in Nairobi, Kenya. ICT4S 2015 conference.

[16] Ericsson. The Next Age of Megacities. 2013. Retrieved February 2018 from https://www.ericsson.com/assets/local/networkedsociety/reports/the-next-age-of-megacities.pdf

[17] Fanny von Heland, Marcus Nyberg, Pontus Westerberg. 2015. Using Minecraft as a citizen participation tool in urban design and decision making. Future of Places conference. Retrieved February 2018 from https://www.ericsson.com/en/conference-papers/using-minecraft-as-acitizen-participation-tool-in-urban-design-and-decision-making

[18] Joakim Formo, 2017. Co-creating the city - City-scale mixed reality tested in Johannesburg. Ericsson blogpost 2017-09. Retieved February 2018 from https://www.ericsson.com/strategicdesign/2017/09/cocreation-the-city-in-mixed-reality/

[19] Executive Office of the President of the United States, Office of Management and Budget. 2007. FEA consolidated reference mode document, version 2.3, October 2007.

[20] International Organization for Standardization (ISO). 2014. ISO 37120:2014 Sustainable development of communities -- Indicators for city services and quality of life. Retrieved from https://www.iso.org/standard/62436.html

[21] JS Walton, M El-Haram, NH Castillo, RMW Horner, ADF Price, and C Hardcastle. 2005. Integrated assessment of urban sustainability, Engineering Sustainability, 158, 2, (June 2005), 57-65. DOI=http://10.1680/ensu.2005.158.2.57

[22] International Telecommunication Union (ITU). 2015. L.1440 Methodology for environmental impact assessment of information and communication technologies at city level.

[23] International Institute of Sustainable development. 2012. Compendium - a global directory to indicator initiatives, http://www.iisd.org/measure/compendium.

[24] International Telecommunication Union (ITU). 2016. L.1601/Y.4901 Key performance indicators related to the use of information and communication technology in smart sustainable cities.

[25] International Telecommunication Union (ITU). 2016. L.1602/Y.4902 Key performance indicators related to the sustainability impacts of information and communication technology in smart sustainable cities.

[26] International Telecommunication Union (ITU). 2016. L.1603/Y.4903 Key performance indicators for smart sustainable cities to assess the achievement of sustainable development goals.

[27] International Organization for Standardization (ISO). ISO ISO/CD 37122 Sustainable development in communities -- Indicators for Smart Cities (under development). Retrieved February 2018 from https://www.iso.org/standard/69050.html

[28] International Organization for Standardization (ISO). ISO ISO/NP 37123 Sustainable Development in Communities -- Indicators for Resilient Cities (under development). Retrieved February 2018 from https://www.iso.org/standard/70428.html

[29] Nigel Simister. 2015. Outputs, Outcomes and Impact. International NGO Training and Research Centre (INTRAC). Retrieved February 2018 from https://www.intrac.org/wpcms/wp-content/uploads/2016/06/Monitoringand-Evaluation-Series-Outcomes-Outputs-and-Impact-7.pdf

[30] Organisation for Economic Co-operation and Development (OECD). 2002 , re-printed in 2010. Glossary of Key Terms in Evaluations and Results Based Management. ISBN 92-64-08527-0. Retrieved February 2018 from www.oecd.org/dac/evaluationnetwork

[31] Anna McCord, Rebecca Holmes, and Luke Harman. 2017. Indicators to measure social protection performance Implications for EC programming. Tools and Methods Series, Concept Paper No 5. Overseas Development Institute (ODI) for European Commission. ISBN 978-92-7964610-2 doi: 10.2841/606804. Retrieved February 2018 from https://europa.eu/capacity4dev/file/32522/download?token=w5yerfsC

[32] Elisabet Bremberg, Helen Slättman, Paul Alarcón. 2015. Skillnadernas Stockholm (in Swedish only). Kommissionen för ett socialt hållbart Stockholm. Retrieved February 2018 from http://www.stockholm.se/PageFiles/1020704/Rapport\%201\%20Skillnadern as\%20Stockholm,\%20juni\%202015.pdf 